\title{
Lipid Lowering and Antioxidant Effects of Newly Synthesized 4-[(Butylsulfinyl)methyl]-1,2-benzenediol (SMBD) in Diet-induced Hypercholesterolemic Rabbits
}

\author{
Hyun Ju Kim, Jeong Sook Noh, Myung Ja Kwon, Suhee Song, ${ }^{\dagger}$ Hongsuk Suh, ${ }^{\dagger}$ Mi Jeong Kim, ${ }^{\dagger}$ and Yeong Ok Song ${ }^{*}$ \\ Department of Food Science and Nutrition, Kimchi Research Institute, Pusan National University, Busan 609-735, Korea \\ *E-mail: yosong@pusan.ac.kr \\ ${ }^{\dagger}$ Department of Chemistry and Chemistry Institute for Functional Materials, Pusan National University, Busan 609-735, Korea \\ ${ }^{\ddagger}$ Department of Food and Nutrition, Silla University, Busan 617-736, Korea
}

Received May 17, 2010, Accepted September 15, 2010

\begin{abstract}
We investigated the effects of newly synthesized 4-[(butylsulfinyl)methyl]-1,2-benzenediol (SMBD) on the prevention of atherosclerosis in hypercholesterolemic rabbits. SMBD exhibited stronger inhibition of $\mathrm{Cu}^{2+}$-induced low-density lipoprotein oxidation than that of ascorbic acid or simvastatin. Three-month-old rabbits were fed an atherogenic diet containing $0.5 \%$ cholesterol and $10 \%$ coconut oil, while other two groups were given an atherogenic diet with intravenous injection of either simvastatin or $\operatorname{SMBD}(0.33 \mathrm{mg} / \mathrm{kg} /$ day $)$ for 4 weeks. The concentrations of plasma cholesterol and thiobarbituric acid reactive substances were significantly decreased in SMBD groups, compared to the control group. Also, aortic lipid level in the SMBD group significantly lower than that in the control group. Furthermore, compared with the control group, the SMBD group significantly inhibited the increase of aortic intimal thickness by $36 \%$ via reducing of aortic reactive oxygen species and cyclooxygenase- 2 protein levels. We conclude that raised antioxidant effect of SMBD results in significant prevention against hypercholesterolemia.
\end{abstract}

Key Words: 4-[(Butylsulfinyl)methyl]-1,2-benzenediol (SMBD), Antioxidant, Oxidative stress, Hypercholesterolemia, Aorta

\section{Introduction}

Dietary cholesterol intake or plasma cholesterol level is a known risk factor directly associated with the development of atherosclerosis. Factors such as oxidation, hypercholesterolemia and inflammation are involved in the progression of atherosclerosis. ${ }^{1,2}$ Oxidative modification of low-density lipoprotein (LDL) has been implied as the initial event in atherosclerosis. Also, hypercholesterolemia increases the production of endothelial $\mathrm{O}_{2}^{-}$by NADPH oxidase in vascular cells and stimulates the early stage of the atherosclerotic process. ${ }^{3}$ More recently, it has been indicated that oxidative stress and vascular diseases involve the cellular production of reactive oxygen species (ROS), which act as an important means of cellular signaling. ${ }^{4}$ Many researchers have cited that endothelial dysfunction enhances the production of ROS and the formation of cyclooxygenase (COX)-dependent vasoconstrictors. ${ }^{5} \mathrm{COX}-2$ generates pro-inflammatory mediators and is expressed in atherosclerotic lesions in humans ${ }^{6}$ and in mice, ${ }^{7}$ whereas COX-2-selective inhibitors are potent anti-inflammatory. ${ }^{8}$ Several epidemiological studies have demonstrated that dietary antioxidants, including polyphenolic compounds, are correlated with a decrease in the risk of atherosclerotic vascular diseases. ${ }^{9-13}$ This led to a gamut of studies using antioxidants, anti-inflammatory compounds and cholesterol-lowering agents to reduce the atherosclerosis in both human and animal models. Therefore, numerous works have been trying to design synthetic derivatives to increase the antioxidant properties. ${ }^{14,15}$ Therefore, we designed this study to test the hypothesis that a SMBD attenuates atherosclerosis by its antioxidative effects in hypercholesterolemic rabbits.

\section{Experimental Section}

Synthesis of SMBD. A synthetic route for the SMBD is shown in Scheme 1. All reagents used were purchased from Aldrich or TCI, and used without further purification. Solvents were purified by normal procedure and handled under a moisturefree atmosphere. ${ }^{1} \mathrm{H}$ and ${ }^{13} \mathrm{C}$ NMR spectra were recorded with a Varian Gemini-300 (300 MHz) spectrometer and chemical shifts were recorded in ppm units with TMS as the internal standard. Flash column chromatography was performed with Merck silica gel 60 (particle size 230 - 400 mesh ASTM) with methanol/methylene chloride gradients unless otherwise indicated. Analytical thin layer chromatography (TLC) was conducted using Merck $0.25 \mathrm{~mm}$ silica gel 60F pre-coated aluminum plates with fluorescent indicator UV254. A high resolution mass spectrum (HRMS) was recorded on a JEOL JMS-700 mass spectrometer under electron impact (EI) conditions in the Korea Basic Science Institute (Daegu, Korea).

For the synthesis of 4-[(butylsulfanyl)methyl]-1,2-benzenediol, 1,2-benzodioxol-5-ylmethanol (5.0 g, $32.86 \mathrm{mmol})$ in

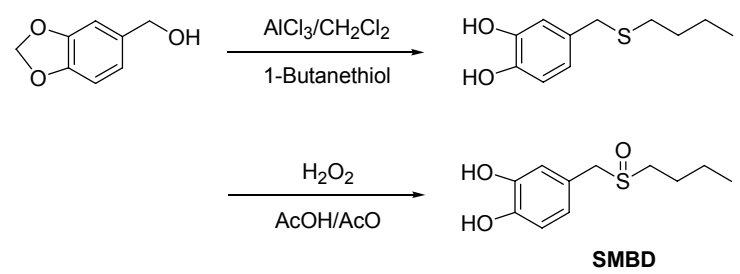

Scheme 1. Synthesis of 4-[(butylsulfinyl)methyl]-1,2-benzenediol (SMBD) 
methylene chloride $(100 \mathrm{~mL})$ was added to a mixture of $\mathrm{AlCl}_{3}$ $(21.9 \mathrm{~g}, 164.4 \mathrm{mmol})$ and 1-buthanethiol $(176 \mathrm{~mL}, 1.64 \mathrm{~mol})$, at $0{ }^{\circ} \mathrm{C}$. The resulting mixture was stirred for $5 \mathrm{~h}$ at room temperature. The mixture was diluted with methylene chloride and aqueous $\mathrm{NH}_{4} \mathrm{Cl}$ was slowly added. The organic phase was isolated and the aqueous phase was extracted with $2 \times 100 \mathrm{~mL}$ of methylene chloride. The combined organic extract was dried with $\mathrm{MgSO}_{4}$, concentrated under reduced pressure, and purified by flash chromatography to give $4.85 \mathrm{~g}(69 \%)$ of compound as a brown oil: $R_{f} 0.35\left(\mathrm{SiO}_{2}, \mathrm{MeOH}: \mathrm{CH}_{2} \mathrm{Cl}_{2}=1: 49\right) ;{ }^{1} \mathrm{H}$ NMR $\left(300 \mathrm{MHz}, \mathrm{CDCl}_{3}\right) \delta 0.96(\mathrm{t}, 3 \mathrm{H}, J=5.8 \mathrm{~Hz}), 1.29-1.60(\mathrm{~m}, 4 \mathrm{H})$, $2.47(\mathrm{t}, 2 \mathrm{H}, J=5.8 \mathrm{~Hz}), 3.63(\mathrm{~s}, 2 \mathrm{H}), 6.7-6.79(\mathrm{~m}, 2 \mathrm{H}), 6.85(\mathrm{~s}$, $1 \mathrm{H}) ;{ }^{13} \mathrm{C}$ NMR $\left(75 \mathrm{MHz}, \mathrm{CDCl}_{3}\right) \delta 13.55,21.88,30.97,31.12$, $35.68,115.34,115.99,121.46,131.19,142.48,143.43$; IR (KBr) $\mathrm{cm}^{-1} 441.8,771.4,1060.8,1442.6,1583.3,1851.4,3696.1$, 3791.6; HRMS (EI) $m / z 212.0871$, calculated for $\mathrm{C}_{11} \mathrm{H}_{16} \mathrm{O}_{2} \mathrm{~S}$ 212.0872 .

To a solution of 4-[(butylsulfanyl)methyl]-1,2-benzenediol $(4.85 \mathrm{~g}, 22.86 \mathrm{mmol})$ in methanol $(5 \mathrm{~mL}), 35 \% \mathrm{H}_{2} \mathrm{O}_{2}(1.53 \mathrm{~mL}$, $22.86 \mathrm{mmol}$ ) was added under argon. The resulting mixture was stirred for $3 \mathrm{~h}$ at $60^{\circ} \mathrm{C}$. The reaction mixture was concentrated under reduced pressure, and purified by flash chromatography to give $3.02 \mathrm{~g} \mathrm{(58 \% )}$ of 4-[(butylsulfinyl)methyl]-1,2-benzenediol (SMBD) as a white solid; $R_{f} 0.3\left(\mathrm{SiO}_{2}, \mathrm{MeOH}: \mathrm{CH}_{2} \mathrm{Cl}_{2}=\right.$ $1: 20) ; \mathrm{mp} 64{ }^{\circ} \mathrm{C} ;{ }^{1} \mathrm{H}$ NMR $\left(\mathrm{CDCl}_{3}\right) \delta 0.81-0.88(\mathrm{t}, 3 \mathrm{H}, J=7.4$ $\mathrm{Hz}), 1.32-1.38$ (m, 2H), 1.60-1.66 (m, 2H), 2.52-2.58 (m, 2H), $3.83(\mathrm{~s}, 2 \mathrm{H}), 6.53-6.71(\mathrm{~m}, 3 \mathrm{H}) ;{ }^{13} \mathrm{C} \mathrm{NMR}\left(75 \mathrm{MHz}, \mathrm{CDCl}_{3}\right)$ $\delta 13.57,21.90,24.57,50.12,57.00,115.63,117.16,120.47$,

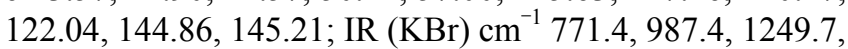
1529.4, 1592.1, 2958.5, 3240.0; HRMS (EI) $\mathrm{m} / \mathrm{z} 228.0820$, calculated for $\mathrm{C}_{11} \mathrm{H}_{16} \mathrm{O}_{3} \mathrm{~S} 228.0816$.

2,2-Diphenyl-1-picrylhydrazyl (DPPH) radical scavenging activity. DPPH radical scavenging activity of SMBD and ascorbic acid was determined using a microplate reader described by Hatano et al. ${ }^{16}$ Briefly, the $100 \mu \mathrm{L}$ of sample diluted with $50 \%$ methanol was mixed with $100 \mu \mathrm{L}$ of $60 \mu \mathrm{M}$ DPPH in $95 \%$ methanol. The reaction mixture was left to stand in the dark for $30 \mathrm{~min}$, and then the optical density was determined at $540 \mathrm{~nm}$ using a microplate reader (model 680, Bio-Rad Laboratories Ltd, UK). The scavenging activity of SMBD and ascorbic acid of DPPH radical was expressed as $\mathrm{IC}_{50}$.

Preparation of LDL and LDL oxidation susceptibility. Human LDL (L-5402, Sigma Chemical Co., St. Louis, MO, U.S.A.) was dialyzed against phosphate buffered saline (PBS) for $20 \mathrm{~h}$ at $4{ }^{\circ} \mathrm{C}$ to remove EDTA, and the protein concentration was determined by the method of Lowry et al. ${ }^{17}$ Oxidation of LDL was carried out according to the methods of Schuh et al. ${ }^{18}$ and Yagi. ${ }^{19}$ Briefly, the oxidation of LDL ( $100 \mu \mathrm{g}$ LDL protein $\left./ \mathrm{mL}\right)$ was induced at $40{ }^{\circ} \mathrm{C}$ by $5 \mu \mathrm{M} \mathrm{CuSO}_{4}$ in PBS in the presence or absence of sample. One milliliter of thiobarbituric acid (TBA)trichloroacetic acid (TCA)- $\mathrm{HCl}$ solution $(0.4 \%$ TBA, $15 \%$ TCA and $2.5 \% \mathrm{HCl}$ ) was added to the mixture, and it was heated at $95-100{ }^{\circ} \mathrm{C}$ for $20 \mathrm{~min}$. TBA-reactive substance (TBARS) was determined by measuring the absorbance at $532 \mathrm{~nm}$. The value of TBARS was expressed in nanomoles of malondialdehyde (MDA) per milligram of LDL protein by a calibration curve constructed from MDA (0 - $25 \mathrm{nmol} / \mathrm{mL})$ in tetramethoxypropane.
Animals and diets. Male New Zealand White rabbits aged 3 months (1.9 - $2.0 \mathrm{~kg}$ ) were purchased from Daehan Animal center Co. Ltd. (Daejeon, Korea). The animals were housed individually in stainless-steel cages in a room at a $23 \pm 2{ }^{\circ} \mathrm{C}$ controlled temperature, relative humidity of $55 \pm 15 \%$, and $12 \mathrm{~h}$ light-dark cycle. Care of the animals and all experimental procedures were conducted in accordance with the institutional guidelines for animal research. After completion of a 2 weeks acclimation period, rabbits were divided by body weight into three groups of seven animals each. The control group was fed a chow diet (Purina) containing $0.5 \%$ cholesterol (w/w) and $10 \%$ coconut oil $(\mathrm{w} / \mathrm{w})$, whereas the other two groups were given a control group diet with SMBD or simvastatin administered at $0.33 \mathrm{mg} / \mathrm{kg} /$ day by intravenous injection via the marginal ear vein every other day for 4 weeks, respectively. The drug doses used were confirmed by prior study that was effective enough for the treatment of hypercholesterolemia. ${ }^{13}$ Diet and drinking water were supplied ad libitum during the experimental periods. The body weights of the animals were monitored during the experiment. At the end of the experiment, rabbits were anesthetized with intravenously administered ketamine $\mathrm{HCl}(50 \mathrm{mg}$ / $\mathrm{mL}$, Korea United Pharmaceuticals, Inc.) after overnight fasting (12 h). Blood samples were collected from the artery, and then the liver and aorta were removed for biochemical analysis.

Analytical procedures of blood and aorta. The plasma total cholesterol, TG, and HDL-cholesterol were determined by enzymatic colorimetric methods using commercial kits (Cholesterol E kit BC 108-E and Triglyceride E kit BC 118, ASAN Pharm. Co., Ltd., Korea). LDL-cholesterol was accomplished according to the procedures described by Friedwald and Levy. ${ }^{20}$ Also, the plasma was analyzed for lipid profile by using an automatic autoanalyzer (Aeroset, Abbott Laboratory) to compare the results obtained from commercial kits. A 3-cm segment of the iliac-femoral artery was used to determine the lipid content of the aorta according to the method of Folch et al. ${ }^{21}$ TBARS concentration of the plasma was measured by using the methods of Schuh et al. ${ }^{18}$ and $\mathrm{Yagi}^{19}$ as previously described in the oxidation of LDL.

Aortic fragments from the aortic arch to iliac-femoral artery were isolated and fixed with a $10 \%$ formalin neutrally buffered solution after the blood had been washed out with saline. The vascular segment (about $3 \mathrm{~mm}$ ) at $5 \mathrm{~mm}$ distance from the bifurcation of the left subclavian artery was embedded in paraffin, and $5-\mu \mathrm{m}$ thick cross sections from each paraffin block were cut and stained with hematoxylin and eosin to determine the thickness of aorta. Images of the aorta were captured with a Nikon digital camera, and the thickness of the aorta was quantified by computer image analysis, using OPTIMAS 6.2 software. The quantification of ROS in aorta was measured on the homogenate with a polytron homogenizer in 7 volumes $(\mathrm{v} / \mathrm{w})$ of ice-cold homogenization solution of the following composition: $50 \mathrm{mM}$ phosphate buffer ( $\mathrm{pH} 7.4$ ), $0.5 \mathrm{mM}$ phenylmethylsulfonyl fluoride, $1 \mathrm{mM}$ ethylenediaminetetraacetic acid disodium salt, 80 $\mathrm{mg} / \mathrm{L}$ trypsin inhibitor and $1 \mu \mathrm{M}$ leupeptin. The homogenate was centrifuged at $900 \times \mathrm{g}$ at $4{ }^{\circ} \mathrm{C}$ for $15 \mathrm{~min}$, and the supernatant was used for western blotting analysis and biochemical assays. ROS generation was measured using a fluorescence probe. ${ }^{22,23}$ Briefly, 2',7'-dichlorofluorescin diacetate (DCFH-DA, Mole- 
cular Probes, Inc., Eugene, OR) was added to the homogenates for a final concentration of $25 \mu \mathrm{M}$. The change in fluorescence intensity was measured every $5 \mathrm{~min}$ for $30 \mathrm{~min}$ on a fluorescence reader (Bio-TEK Instruments, Inc., Winooski, VT) at an excitation of $485 \mathrm{~nm}$ and emission of $530 \mathrm{~nm}$. ROS status was calculated as fluorescence per min. The western blot of cyclooxygenase (COX)-2 in aorta was carried out as described previously. ${ }^{24,25}$ The protein was separated by a SDS-polyacrylamide mini-gel as described by Laemmli. ${ }^{26}$ Antibody against COX-2, $\beta$-actin and HRP-conjugated secondary antibodies were obtained from Santa Cruz Biotechnology Inc. (Santa Cruz, CA, U.S.A.). Antibody labeling was detected using enhanced chemiluminescence (Amersham Life Science, Inc. Arlington Heights, IL, U.S.A.) and exposed to radiographic film. Pre-stained blue protein marker was used for molecular weight determination. The concentration of total protein in the samples was measured with Sigma protein assay reagent kit containing bicinchoninic acid.

Statistical analysis. Statistical analyses were performed using Statistical Analysis Software (SAS Institute). The results are presented as means and standard deviation. The significance of the difference between groups was analyzed by one-way ANOVA followed by Duncan's multiple range tests. Values of $p<0.05$ were considered to be significant.

\section{Results}

The $\mathrm{IC}_{50}$ for $\mathrm{DPPH}$ radical scavenging activity of SMBD and ascorbic acid were shown in the Table $1 . \mathrm{IC}_{50}$ for SMBD was significantly lower than that of ascorbic acid, exhibiting higher DPPH radical scavenging activity $(p<0.05)$. As shown in Figure 1, the increase of TBARS during incubation of LDL with $\mathrm{Cu}^{2+}$ was inhibited by SMBD, which showed a relatively strong inhibitory effect compared to ascorbic acid and simvastatin. Body, liver weights, as well as plasma lipid levels as well as TBARS concentrations are shown in Table 2 . Body weights of the rabbits at the start of the experiment were similar for all

Table 1. $\mathrm{IC}_{50}$ for DPPH radical scavenging activity of $\mathrm{SMBD}^{1)}$ and ascorbic acid

\begin{tabular}{cc}
\hline & $\mathrm{IC}_{50}(\mu \mathrm{g} / \mathrm{mL})$ \\
\hline SMBD & $1.73 \pm 0.13^{\mathrm{b}}$ \\
Ascorbic acid & $5.76 \pm 0.48^{\mathrm{a}}$ \\
\hline
\end{tabular}

$\overline{\mathrm{a} \sim \mathrm{b}}$ Data with different letters are significantly different with ANOVA followed by Duncan's multiple range test at $p<0.05$. ${ }^{1)}$ See the Scheme 1.

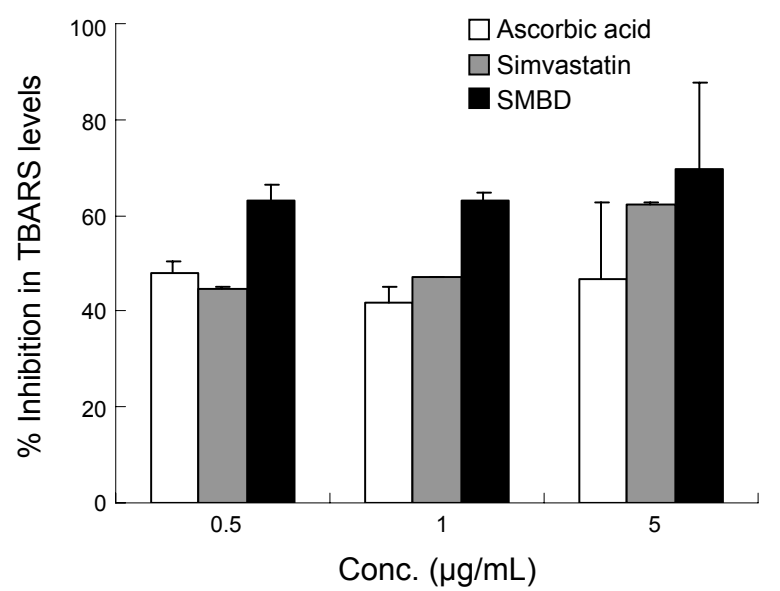

Figure 1. In vitro inhibitory effect on $\mathrm{Cu}^{2+}$-mediated $\mathrm{LDL}$ oxidation measured as TBARS generation over an incubation period of $\mathbf{4 h}$. Results are expressed as percent changes in TBARS generation relative to LDL oxidized in the absence of sample and calculated as the mean of at least three independent experiments performed in triplicate.

three groups. Body weight gain was slightly lower in the SMBD and simvastatin groups than control, but there were no significant differences among the groups. Hypercholesterolemia was confirmed in the control group with total cholesterol concentrations over $1700 \mathrm{mg} / \mathrm{dL}$ by a $0.5 \%$ cholesterol diet for 4 weeks. Among lipid profiles, total cholesterol and LDL-cholesterol concentration levels were significantly lower in the simvastatin and SMBD groups than in the control group. TG levels in the SMBD group were slightly decreased by $12 \%$, but were not significant compared with the other groups. HDL-cholesterol level was not changed during the study. The level of plasma TBARS was significantly lowered in the simvastatin and SMBD group compared to that of the control group by $26 \%$ and $35 \%$, respectively. Figure 2 shows the intimal and total thickness of the aorta in $0.5 \%$ cholesterol diet fed-rabbits for 4 weeks. The simvastatin and SMBD groups had significantly reduced intimal thickness compared to the control group by $38 \%$ and $36 \%$, respectively $(p<0.05)$. The total thickness of the aorta was slightly reduced in the SMBD group $(p<0.05)$, but the thickness of the media and external of the aorta remained the same (data not shown). As shown in Figure 3, the TC content in the aorta of the SMBD group was significantly suppressed compared to both the simvastatin and control groups. However, a significant decrease in TG concentration in both SMBD and simvastatin groups were observed $(p<0.05)$ (Figure 3). Figure 4 shows ROS generation and COX-2 protein levels of the aorta in $0.5 \%$ cholesterol diet-

Table 2. Effect of $\mathrm{SMBD}^{1)}$ on body, liver weights, plasma lipid and TBARS concentrations of rabbits fed a $0.5 \%$ cholesterol diet for 4 weeks

\begin{tabular}{cccccccc}
\hline Group $^{2)}$ & $\begin{array}{c}\text { Gained Body } \\
\text { weight }(\mathrm{kg})\end{array}$ & $\begin{array}{c}\text { Liver weight } \\
(\mathrm{g})\end{array}$ & $\begin{array}{c}\text { Total cholesterol } \\
(\mathrm{mg} / \mathrm{dL})\end{array}$ & $\begin{array}{c}\text { LDL-cholesterol } \\
(\mathrm{mg} / \mathrm{dL})\end{array}$ & $\begin{array}{c}\text { HDL-cholesterol } \\
(\mathrm{mg} / \mathrm{dL})\end{array}$ & $\begin{array}{c}\text { Triglyceride } \\
(\mathrm{mg} / \mathrm{dL})\end{array}$ & $\begin{array}{c}\text { TBARS } \\
(\mathrm{nmol} / \mathrm{mL} \text { plasma })\end{array}$ \\
\hline Control & $0.65 \pm 0.19^{\mathrm{NS}}$ & $106.7 \pm 9.5^{\mathrm{NS}}$ & $1706.7 \pm 321.7^{\mathrm{a}}$ & $1354.1 \pm 285.8^{\mathrm{a}}$ & $49.2 \pm 3.8^{\mathrm{NS}}$ & $334.3 \pm 37.3^{\mathrm{NS}}$ & $100.1 \pm 12.4^{\mathrm{a}}$ \\
Simvastatin & $0.61 \pm 0.17$ & $103.8 \pm 6.4$ & $1493.3 \pm 441.1^{\mathrm{ab}}$ & $1166.1 \pm 373.8^{\mathrm{ab}}$ & $57.0 \pm 10.4$ & $313.3 \pm 66.7$ & $74.2 \pm 10.8^{\mathrm{b}}$ \\
SMBD & $0.58 \pm 0.24$ & $98.2 \pm 10.9$ & $1278.3 \pm 173.0^{\mathrm{b}}$ & $976.2 \pm 135.2^{\mathrm{b}}$ & $44.8 \pm 24.8$ & $293.2 \pm 40.5$ & $65.1 \pm 9.8^{\mathrm{b}}$ \\
\hline
\end{tabular}

Values are presented as mean $\pm \mathrm{SD}(\mathrm{n}=7)$. Data in the column indicates statistically significant among different groups at 0.05 level. ${ }^{1)}$ See the Scheme 1 . ${ }^{2)}$ Control group fed $0.5 \%$ cholesterol and $10 \%$ coconut oil, and injected saline $0.33 \mathrm{~mL} / \mathrm{kg} / \mathrm{day}$. SMBD group fed $0.5 \%$ cholesterol and $10 \%$ coconut oil, and SMBD was injected $0.33 \mathrm{mg} / \mathrm{kg} / \mathrm{day}$. Simvastatin group fed $0.5 \%$ cholesterol and $10 \%$ coconut oil, and simvastatin was injected $0.33 \mathrm{mg} / \mathrm{kg} / \mathrm{day}$. 


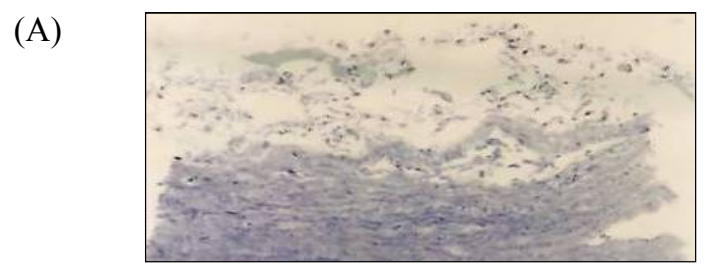

(B)

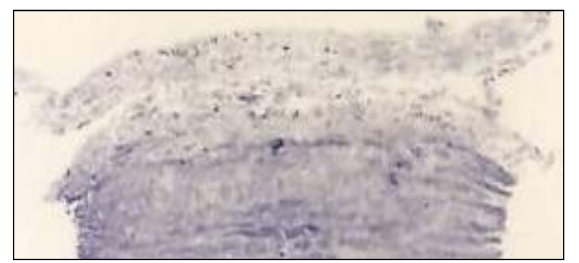

(C)

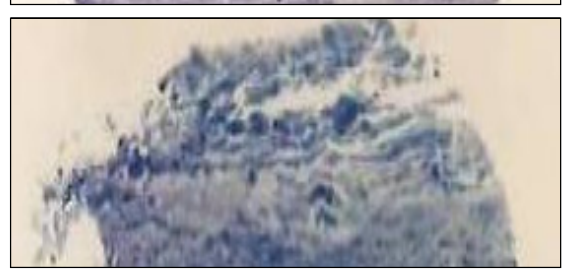

(D)

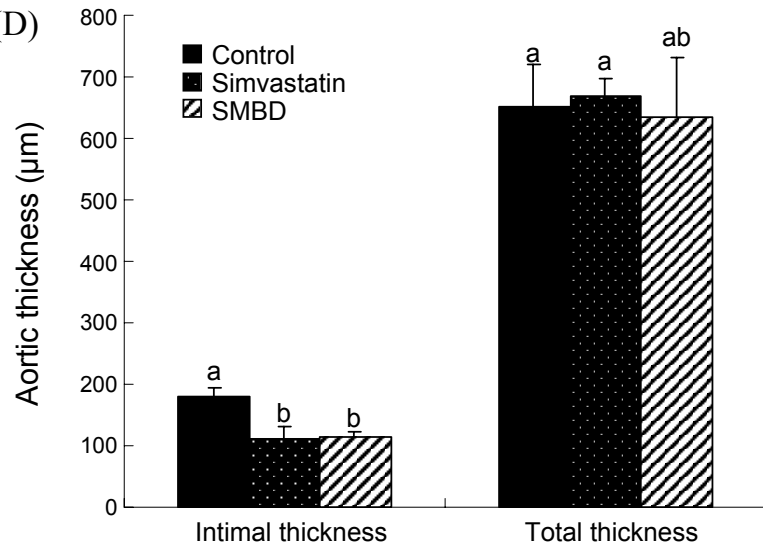

Figure 2. Effect of SMBD ${ }^{1)}$ on aorta tissue morphology and aortic thickness of rabbits ${ }^{2)}$ fed a $0.5 \%$ cholesterol diet for 4 weeks. (A C) Hematoxylin and eosin-stained section $(\times 200)$ and (D) the total and intimal thickening were evaluated in aorta. Values are mean $\pm \operatorname{SD}(n=$ 7). ${ }^{\mathrm{a} \sim \mathrm{b}}$ Data in the column are significantly different by one-way ANOVA followed Duncan's multiple range test at 0.05 level of significance. ${ }^{1)}$ See the Scheme $1 .{ }^{2)}$ See the legend of Table 2.

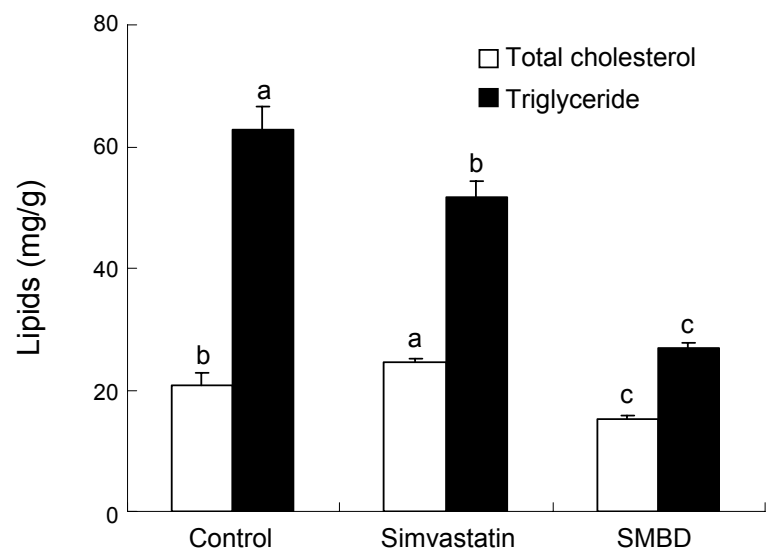

Figure 3. Effect of $\mathrm{SMBD}^{1)}$ on lipid contents in the aorta of rabbits ${ }^{2)}$ fed a $0.5 \%$ cholesterol diet for 4 weeks. Values are mean $\pm S D(n=7)$. ${ }^{a-b}$ Data in the column are significantly different by one-way ANOVA followed Duncan's multiple range test at 0.05 level of significance. ${ }^{1)}$ See the Scheme $1 .{ }^{2}$ See the legend of Table 2.
(A)

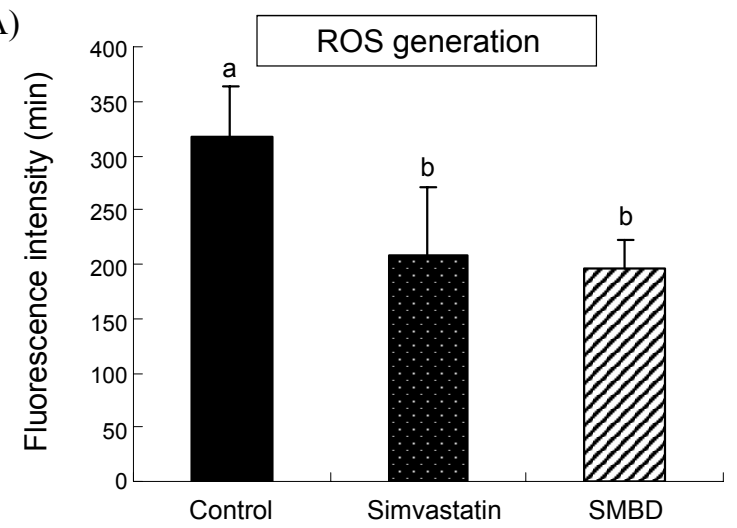

(B)

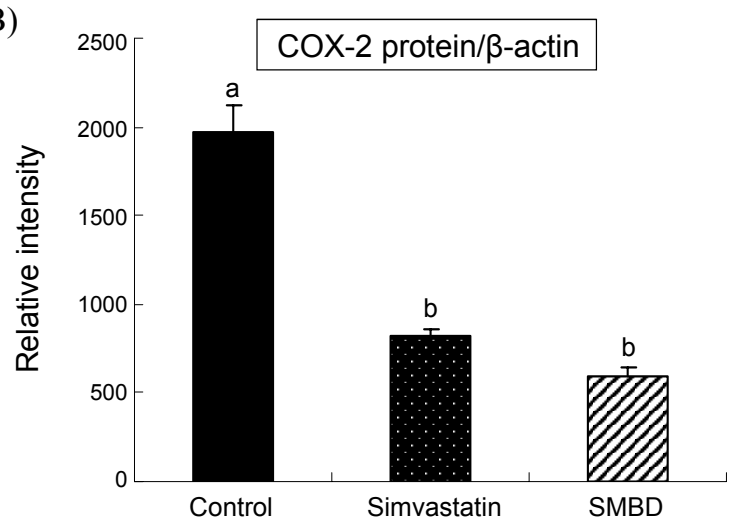

Figure 4. The effect of SMBD ${ }^{1)}$ on ROS generation and COX-2 protein levels in the aorta of rabbits ${ }^{2)}$ fed a $0.5 \%$ cholesterol diet for 4 weeks. Values are mean $\pm \mathrm{SD}(\mathrm{n}=7)$. (A) The ROS generation was estimated by staining with fluorometer using DCF-DA and DAF-2DA, respectively. (B) The expression of COX-2 protein was determined by Western-blot analysis. Quantitation of the COX-2 protein expression was performed by densitometric analysis. ${ }^{\mathrm{a} b}$ Data are significantly different by one-way ANOVA followed Duncan's multiple range test at 0.05 level of significance. ${ }^{1)}$ See the Scheme $1 .{ }^{2)}$ See the legend of Table 2.

fed rabbits. ROS generation in the aorta was markedly increased by 3.3 times in the control group compared with those in the normal group (data not shown, $p<0.05$ ). In contrast, the generation of ROS in the simvastatin and SMBD group was reduced by $35 \%$ and $38 \%$ compared with the control group, respectively $(p<0.05)$. COX-2 protein expression in the aorta of the control group was markedly increased by 19 times compared with the normal group (data not shown, $p<0.05$ ). In contrast, COX-2 protein expression in the simvastatin and SMBD groups significantly decreased by $24 \%$ and $70 \%$ compared with the control group, respectively.

\section{Discussion}

The aim of this study was to assess the effect of a newly synthesized SMBD on hypercholesterolemic rabbits. As shown in Scheme 1, the antioxidant capacity of SMBD comes from the ortho di-hydroxyl group of the benzene ring (catechol functionality). The hydroxyl hydrogen of the catechol can be successively abstracted, finally forming a stable quinine structure. ${ }^{27}$ The 
antioxidant capacity of natural antioxidant is exerted through the phenolic hydroxy group, which readily donates its hydrogen atom to the radical, resulting in the formation of a stable molecule. ${ }^{28}$ Furthermore, dimethylsulfoxide (DMSO) which contains sulfur group and is a part of structure of SMBD has been reported to be an effective scavenger of reactive oxygen radicals. ${ }^{29}$ In this study, SMBD was exhibited stronger DPPH radical scavenging activity compared with that of ascorbic acid, and reduced LDL susceptibility to oxidation as measured by TBARS. Such inhibitory effect in oxidized LDL (oxLDL) system also suggests that SMBD may have free radical scavenging effect. There are several reports on natural antioxidative substances which are able to protect endothelial cells from oxLDL cytotoxicity and exert anti-atherosclerotic effect through an antioxidant mechanism involving inhibition of intracellular signaling events. $^{30,31}$

Our results showed that in hypercholesterolemia which induced by $0.5 \%$ cholesterol diet for 4 weeks, plasma total and LDL-cholesterol levels in SMBD and simvastatin groups were lower than those in the control group. Consistently with our data, some studies reported that statins and the synthetic derivatives from natural phenolic antioxidants are effective not only in lowering lipid levels, but also in suppressing development of atherosclerotic lesion and oxidative stress in cholesterol dietinduced hypercholesterolemic rats and rabbits. ${ }^{32-34} 3$-Hydroxy3-methyl-glutaryl (HMG)-CoA reductase inhibitors (statins) are potent inhibitors of cholesterol biosynthesis in the liver by blocking the conversion of HMG-CoA to mevalonate, the ratelimiting step in the mevalonate pathway. ${ }^{13}$ Also, several studies have demonstrated that statins have pleiotropic effects such as the reduction of endothelial dysfunction, inhibition of inflammatory responses, stabilization of atherosclerotic plaques, and modulation of procoagulant activity and platelet function. ${ }^{35}$ The present study demonstrated that SMBD also interrupted the progression of atherosclerotic lesion, possibly owing, in part, to a decrease in lipid and TBARS levels in plasma, aortic ROS generation and COX-2 protein expression in hypercholesterolemic rabbits. Several studies have shown that hypocholesterolemic agents possessing antioxidant activity showed anti-atherosclerotic effects at high doses due to lowering of plasma cholesterol levels, while suppressing the development of atherosclerotic lesions at low doses due to their antioxidative effects on LDL oxidation. ${ }^{36-38}$ Similarly, SMBD at a dose of $0.33 \mathrm{mg} / \mathrm{kg} /$ day not only significantly lowered the plasma lipid levels, but also diminished the atherosclerotic lesion by its antioxidant activity. In the present study, histological examination of the arterial lesions revealed typical characteristic features of early atherosclerosis in the control group, which was mainly caused by the accumulation of lipid-laden foam cells in the sub-endothelial space, but no morphological alterations generally seen in more advanced disease were observed. Hence, we speculated that SMBD significantly inhibits a certain process in the early cellular events of atherosclerosis, which may be implicated in the oxidation and inflammation mechanism. ${ }^{39}$ Quiles et al. ${ }^{40}$ reported that rabbits fed an atherogenic diet containing $1.3 \%$ cholesterol and 3\% lard showed a significant increase in plasma lipid peroxidation and fatty streak lesions, and decreased levels of antioxidants at 30 days. Hypercholesterolemia impairs endo- thelial function, which is one of the earliest manifestations of atherosclerosis. ${ }^{41}$ Oxidative stress has been implicated as an important etiologic factor in atherosclerosis and vascular dysfunction, whereas antioxidants may inhibit atherogenesis and improve vascular function. ${ }^{42}$ In addition, the superoxide anion may react with nitric oxide, results in LDL modification and lipid accumulation within the vascular wall of hypercholesterolemic animals. ${ }^{41}$ Oxidation of LDL is considered an important step and seems to modulate cellular gene expression by the upregulation pathway of transcription factors in the development of atherosclerosis. ${ }^{4}$ Our results confirmed that SMBD directly inhibits the development of atherosclerosis, at least to a certain extent, through the decrease of ROS generation and COX-2 protein expression in the aorta. Recent studies have shown that COX-2 is expressed in human atherosclerotic lesions by the endothelial cells, smooth muscle cells, and macrophages. Also, COX-2-mediated eicosanoid production by activated macrophages may promote the atherosclerosis through several mechanisms, including activation of chemotaxis, increasing vascular permeability, propagation of the inflammatory cytokine cascade, and stimulation of macrophage and smooth muscle cell migration. ${ }^{7}$ On the other hand, COX-2 inhibitors may promote the development of cardiovascular events by inhibiting prostacyclin, a strong endogenous platelet antagonist, thus inducing a prothrombotic state. ${ }^{43}$ In the present study, the inhibition of intimal hyperplasia in the SMBD group was observed to be similar to that of simvastatin, and thought to be caused by suppressing the inflammatory process in atherosclerotic lesion by inhibiting macrophage recruitment, and proliferation and migration of SMCs. Moreover, many transcription factors are regulated by oxygen radicals, and ROS generation in stimulated macrophages is involved in COX-2 induction. ${ }^{44}$ A detailed mechanism on anti-atherosclerotic effect of SMBD will be explored in future studies.

In conclusion, our data show that SMBD has lipid lowering and antioxidant effect by lowering plasma lipid levels and by decreasing aortic thickness, ROS generation and COX-2 protein expression in cholesterol diet-induced hypercholesterolemic rabbits for 4 weeks. These data suggest that SMBD is a useful new compound to help reduce atherosclerosis which is induced by hypercholesterolemia. These observations suggest that a newly synthesized SMBD might provide as a therapeutic agents in atherosclerosis.

Acknowledgments. This work was supported for 2 years by a Pusan National University Research Grant. The authors have declared no conflict of interest statement.

\section{References}

1. Berliner, J. A.; Navab, M.; Fogelman, A. M.; Frank, J. S.; Demer, L. L; Edwards, P. A.; Watson, A. D.; Lusis, A. J. Circulation 1995, 91, 2488.

2. Lusis, A. J. Nature 2000, 407, 233.

3. Galle, J.; Hansen-Hagge, T.; Wanner, C.; Seibold, S. Atherosclerosis 2006, 185, 219.

4. Chen, K.; Thomas, S. R.; Keaney, J. F. Free Radic. Biol. Med. 2003, $15,117$.

5. Landino, L. M.; Crews, B. C.; Timmons, M. D.; Morrow, J. D.; 
Marnett, L. J. Proc. Nat. Acad. Sci. USA 1996, 93, 15069.

6. Schonbeck, U.; Sukhova, G. K.; Graber, P.; Coulter, S.; Libby, P. Am. J. Pathol. 1999, 155, 1281.

7. Burleigh, M. E.; Babaev, V. R.; Oates, J. A.; Harris, R. C.; Gautam, S.; Riendeau, D.; Marnett, L. J.; Morrow, J. D.; Fazio, S.; Linton, M. F. Circulation 2002, 105, 1816.

8. Cipollone, F.; Fazia, M. L. J. Cardiovasc. Pharmacol. 2006, 47, S26.

9. Bravo, L. Nutr. Rev. 1998, 56, 317.

10. Kaliora, A. C.; Dedoussis, G. V. Z.; Schmidt, H. Atherosclerosis 2006, 187, 1 .

11. Diaz, M. N.; Frei, B.; Vita, J. A.; Keaney, J. F. N. Engl. J. Med. 1997, 337, 408.

12. Gotto, A. M. Am. J. Med. 2002, 112, 10.

13. Igel, M.; Sudhop, T.; von Bergmann, K. Eur. J. Clin. Pharmacol. 2001, 57, 357.

14. Palozza, P.; Simone, R.; Picci, N.; Buzzoni, L.; Ciliberti, N.; Natangelo, A.; Manfredini, S.; Vertuani, S. Free Radic. Biol. Med. 2008, 44, 1452.

15. Siddaiah, V.; Maheswara, M.; Venkata Roa, C.; Venkateswarlu, S.; Subbaraju, G. V. Bioorg. Med. Chem. Lett. 2007, 17, 1288.

16. Hatano, T.; Edamatsu, R.; Hiramatsu, M.; Mori, A.; Fujita, Y.; Yasuhara, T.; Yoshida, T.; Okuda, T. Chem. Pharm. Bull. 1989, 37, 2016.

17. Lowry, O. H.; Rosebrough, N. J.; Farr, A. L.; Randall, R. J. J. Biol. Chem. 1951, 193, 265.

18. Schuh, J.; Fairclough, G. F.; Haschemeyer, R. H. Proc. Natl. Acad. Sci. USA 1978, 75, 3173.

19. Yagi, K. Methods Mol. Biol. 1998, 108, 101.

20. Friedwald, W.; Levy, R. I. Clin. Chem. 1972, 18, 494.

21. Folch, J.; Lees, M.; Sloane-Stanley, G. H. J. Biol. Chem. 1957, $226,497$.

22. Cathcart, R.; Schwiers, E.; Ames, B. W. Methods Enzymol. 1984, $105,352$.

23. LeBel, C. P.; Ischiropoulos, H.; Bondy, S. C. Chem. Res. Toxicol. 1992, 5, 227

24. Oberley, L. W. Free Radic. Biol. Med. 1988, 5, 113.
25. Zou, Y.; Jung, K. J.; Kim, J. W.; Yu, B. P.; Chung, H. Y. FASEB J. 2004, 18, 320.

26. Laemmli, U. K. Nature 1970, 227, 680.

27. Tejero, I.; Gonzalez-García, N.; Gonzalez-Lafont, A.; Lluch, J. M. J. Am. Chem. Soc. 2007, 129, 5846.

28. Hanasaki, Y.; Ogawa, S.; Fukui, S. Free Radic. Biol. Med. 1994, 16,845 .

29. Wakata, N.; Sugimoto, H.; Iguchi, H.; Nomoto, N.; Kinoshita, M. Neurochem. Res. 2001, 26, 841.

30. Owen, P. L.; Matainaho, T.; Sirois, M.; Johns T. J. Biochem. Mol. Toxicol. 2007, 21, 231.

31. Ross, R.; Glomset, J. A. Science 1973, 180, 1332.

32. Bolayirli, I. M.; Aslan, M.; Balci, H.; Altug, T.; Hacibekiroglu, M.; Seven, A. Life Sci. 2007, 81, 121.

33. Kim, S. J.; Bok, S. H.; Lee, S.; Kim, H. J.; Lee, M. K.; Park, Y. B.; Choi, M. S. Toxicol. Appl. Pharmacol. 2005, 208, 29.

34. Kim, H. J.; Lee, J. S.; Chung, H. Y.; Song, S. H.; Suh, H.; Noh, J. S.; Song, Y. O. J. Agric. Food Chem. 2007, 55, 10486.

35. Takemoto, M.; Liao, J. K. Arterioscler. Thromb. Vasc. Biol. 2001, 21,1712 .

36. Nagano, Y.; Nakamura, T.; Matsuzawa, Y.; Cho, M.; Ueda, Y.; Kita, T. Atherosclerosis 1992, 92, 131.

37. Yamaguchi, Y.; Matsuno, S.; Kagota, S.; Haginaka, J.; Kunitomo, M. Eur. J. Pharmacol. 2002, 436, 97.

38. Shakuto, S.; Oshima, K.; Tsuchiya, E. Atherosclerosis 2005, 182, 209.

39. Libby, P. Nature 2002, 420, 868.

40. Quiles, J. L.; Mesa, M. D.; Ramírez-Tortosa, C. L.; Aguilera, C. M.; Battino, M.; Gil, A.; Ramírez-Tortosa, M. C. Arterioscler. Thromb. Vasc. Biol. 2002, 22, 1225.

41. Ohara, Y.; Peterson, T. E.; Harrison, D. G. J. Clin. Invest. 1993, $91,2546$.

42. Frei, B. Proc. Soc. Exp. Biol. Med. 1999, 222, 196.

43. Cheng, Y.; Austin, S. C.; Rocca, B.; Koller, B. H.; Coffman, T. M.; Grosser, T.; Lawson, J. A.; FitzGerald, G. A. Science 2002, $296,539$.

44. Valledor, A. F.; Ricote, M. Biochem. Pharmacol. 2004, 67, 201. 